\title{
THE MEDICAL SUPPORT OF A SMALL AIR-LANDED FORCE
}

\author{
Major A. J. SHAW, M.A., M.B., B.Chir., D.T.M. \& H., D.Obst.R.C.O.G., R.A.M.C. \\ 8 Casualty Clearing Station
}

IN recent years much interest has centred on the problems of providing small, highly trained forces, primarily air-transported and air-landed to react rapidly to a counterinsurgency or limited war situation. These forces are unlikely, initially, to exceed a brigade or at most, two brigades in size.

It is the task of the Royal Army Medical Corps (R.A.M.C.) to provide such forces with effective medical support. Because of the endless variations of situation which could present, a very flexible field organisation is required if reaction is to be both effective and sufficiently rapid. This, it would appear, the R.A.M.C. has or will have when the present reorganisation and re-scaling programme is completed. However, the adequate support cannot be provided from any one type of medical unit because a combination of second and third line cover will be needed from the outset.

It is suggested that the initial medical support for such a situation would consist of a field ambulance with a casualty clearing station (C.C.S.) detachment under command. The practical problems set by this amalgamation of two types of medical unit are the subject of this paper.

\section{A typical situation}

A situation in limited war or counter-insurgency operations might arise as follows. A brigade-size force is flown from a mounting base, either in the United Kingdom or overseas, to a probably secured air-head in the theatre of operations. The force uses this air-head as its firm base, and fighting units deploy from it for up to 40-50 miles. As operations extend to greater depth, a smaller advance air-head might be established later. At first, the brigade would be dependent on air re-supply and reinforcement from the mounting base, possibly five to eight hours flying time away, in transport aircraft, strategic or tactical (medium range). After perhaps two to four weeks at least, a sea lift might arrive and a formal logistic base would be built up in the theatre of operations. The time between the arrival of the air-transported brigade and that of the logistic support by sea is vital, and of particular interest.

Several factors are at once obvious. Firstly, however good the Royal Air Force transport capacity is or may become, air-space for both personnel and freight will be severely limited, and clearly priority must be given to fighting troops and combat supplies. Our medical support at the start must therefore be strictly tailored in both personnel and freight. Secondly, it must be assumed that the brigade will sustain casualties fairly soon, if not immediately, after landing. Thirdly, the flying time to the mounting base is too great to give First Priority casualties the best chance of survival if they are to depend upon surgery at a hospital in the mounting base. Fourthly, with the small numbers of men involved, evacuation of minor sick for treatment in the mounting base is likely to produce an unacceptable strain on the resources of the force. Minor sick in this context are taken to be men who, with good medical care, could be returned to their units within a week to ten days.

From the outset, therefore, the task of the R.A.M.C. must be primarily to provide 
surgery and resuscitation for first priority casualties, and to prevent over-evacuation of minor sick by holding and treating them in the theatre of operations. This must be done with the minimum of personnel and equipment because of the restrictions of the air-lift. The suggested solution is to place a surgical team and a nursing team (25-50 beds) of the C.C.S. under command of the brigade field ambulance, the remainder of the C.C.S. following up in the sea-lift. Until recently it has been the custom to place solely a surgical team under field ambulance command, but it is clear that skilled nursing and adequate field ward facilities must be provided for postoperative cases if major surgery is to be successful. Some of the practical problems arising from this amalgam are worthy of discussion.

\section{Personnel}

In the new C.C.S. establishment a surgical team includes a Queen Alexandra's Royal Army Nursing Corps (Q.A.R.A.N.C.) theatre sister, and each 50-bed nursing team consists of four Q.A.R.A.N.C. sisters and nine R.A.M.C. nurses. It is clearly inappropriate for Q.A.R.A.N.C. sisters to be included in this initial detachment. While the theatre sister can possibly be omitted (three operating theatre technicians are available) the four Q.A.R.A.N.C. ward sisters must be replaced by R.A.M.C. nurses if sufficient personnel are to be provided to run the ward.

Because of the restrictions on air passenger space it is essential to keep numbers to a minimum. The C.C.S. detachment must therefore be limited to theatre and ward staff. There can be no room for the usual general duty personnel so essential to the smooth running of a unit in the field. Thus, to write baldly " detachment C.C.S. under command of field ambulance" understates the burden which in practical terms is being placed on the field ambulance. The detachment is sufficiently large to set up its own canvas and set out its own equipment. Once this is done, if, as is more than likely, casualties begin to arrive, it will be fully occupied in treating them.

Latrines must be dug, defences prepared, food and water carried for patients, stretcher bearers provided, documentation carried out and generators tended and refuelled. Much depends upon how soon casualties arrive but all these tasks may of necessity fall to the field ambulance, in addition to the obvious ones of rationing and administering the additional personnel. These duties can become considerable and it is clear that forethought and liaison between C.C.S. and field ambulance is imperative if a smooth working amalgamation is to be achieved.

\section{Defence and weapons}

A field ambulance is equipped to set up tactically, to conceal itself and to defend itself if the need arises. To this end, all personnel are armed, and tentage and vehicles are provided with camouflage nets. A C.C.S. has only a small percentage of armed personnel and requires so large an area to set up its wards that a red cross flag is provided in lieu of camouflage nets. Indeed, the existing hospital marquee would defy the most expert camoufiage methods in the most convenient of woods! Clearly, the C.C.S. detachment must adopt the field ambulance methods, particularly since it will be situated near an air-head probably as part of the Brigade Administrative Area (B.A.A.) and initially at least, will be under threat. The detachment must therefore discard the hospital 
marquees at present scaled to the C.C.S. and, until the new field medical structures are available, should be housed in universal shelters which must be camouflaged.

The problem of arming the C.C.S. is more complex. It raises an issue on which personalities in our Corps are divided and hold equally strong and diametrically opposed views. It may be argued that the C.C.S. detachment, consisting of wholly professional theatre and ward staff, will be too fully occupied with treating their patients to spare time to defend them. What, however, would the sleeping, off-duty ward staff do if the unit were attacked? They must stand to, and would clearly be happier with a weapon in their hands. This subject could by itself form the subject of a separate paper. Suffice it to suggest here that at least a proportion of the detachment should be armed. "When in Rome......"

\section{Freight and transport}

It is estimated that to carry the personnel and equipment of a surgical team and a 50-bed nursing team, five 3-ton cargo and one $\frac{1}{4}$ or $\frac{3}{4}$ ton vehicles would be required, the generator and the sterilizer being towed. The bill could be cut by one 3-ton vehicle if only 25 beds were required. These vehicles cannot be provided by the C.C.S. and should not be provided by the field ambulance, the transport of which is fully earmarked for its own personnel and equipment. Once, however, the detachment is set up and holding casualties it will be unlikely to move and therefore only a one-time lift is the probable requirement. Allowance must be made for this lift however, or precious hours may be wasted before the detachment can become functional. If substantial road movement is likely in a given situation it would be desirable to earmark this scale of transport for the C.C.S. detachment at the outset.

\section{Tactical deployment and chain of evacuation}

Two hallowed tenets of field ambulance doctrine have been " Thou shalt not hold" and "Thou shall be capable of moving within two hours". These tenets cannot hold good in the type of situation under discussion.

Once the C.C.S. detachment has, received and operated on casualties it is clearly static. It is dependent for its daily existence on the administrative resources and general duty personnel of the field ambulance. This implies that the majority of the headquarters and bearer platoon of the Advance Dressing Station (A.D.S.) must remain with it.

What of the clearing platoon? The primary function of the clearing platoon is the sorting of casualties. If this function is carried out away from the surgical complex, delays will result which could cost lives. The medical officer responsible for sorting casualties in the Reception of the A.D.S. must be continually aware of the bed occupancy in the ward and the capability of the surgeon. Only in this way can he decide as rapidly as possible which casualties are to be held for surgery and which are to be flown out to the mounting base. A second function of the clearing platoon in this situation may be to assist in the treatment of ward patients. It is possible that the whole C.C.S. nursing team will be employed in treating surgical casualties, and may require the assistance of the clearing platoon, reinforced if necessary by a collecting section, to run 25 beds from the C.C.S. equipment as the "medical ward ". Clearly the arrangement will vary with the casualty rate, but the responsibility for the " medical cases" may of necessity rest with the clearing platoon even if the ward equipment is provided by the C.C.S. detachment. 
To summarise, the A.D.S. and the C.C.S. detachment must work as an integrated medical unit. It follows, therefore, that once casualties are received, the major part of the A.D.S. must remain static until relieved by the arrival of the remainder of the C.C.S. by air.

\section{Command and Control}

The necessity for the A.D.S./C.C.S. detachment to remain stable may well provide a problem in command and control. It is possible that the brigade may move forward as far as $\mathbf{5 0}$ miles from its air-head and even establish a small tactical air-head forward. Brigade headquarters will obviously move forward as will probably the greater part of the B.A.A. Three medical " echelons" will then be required, the collecting sections with the battalions, the A.D.S./surgical complex at the air-head, and a medical " control element" somewhere in-between, probably near or with brigade headquarters. It is here that the value of the collecting company headquarters can be realised and although it exists only in the war establishment of the new field ambulance it is hoped that it would be implemented for this type of operation. It is probable that the officer commanding the field ambulance would have to base himself near brigade headquarters, where he could most easily control medical activity, forward and to the rear.

\section{Conclusion}

The problems of medical support of a brigade air-transported into a counterinsurgency or limited war situation have been outlined. The amalgamation of a C.C.S. detachment with a field ambulance has been discussed. These field units are fundamentally different in their equipment, tactical deployment and role. Unless both are fully aware of the way in which the other functions and have trained closely together to achieve a method, many " teething" troubles will occur, time for which cannot be afforded when faced with the real thing.

\section{Medicine and Surgery in the Great War 1914-1918}

On 11th November, 1968, Lieutenant-General Sir Robert Drew opened an exhibition at the Wellcome Building, Euston Road, London.

Sponsored by the Wellcome Institute of the History of Medicine, this is in commemoration of the 50th anniversary of the Armistice. A collection of instruments, equipment and medicines used in the Great War is complemented by paintings, photographs, books and posters.

Among many items on show, lent by the Army Medical Services, are the portraits of Lieutenant-General Sir Alfred Keogh, and of Lieutenant-General Sir Arthur Sloggett, which normally hang in the dining room of the R.A.M.C. Headquarter Mess, the Horrocks' Box, and uniforms as worn by the Army nursing services of the day.

The exhibition is open to the public until May 1969. 